\title{
THE ROLE OF PERSONALIZED EDUCATION TOOLS IN COMPUTER PROGRAMMING LEARNING
}

\author{
Fadhla Junus
}

State Islamic University (UIN) Ar-Raniry, Indonesia

\begin{abstract}
The proliferation of information and communication technology (ICT) which is followed by the high demand of ICT tools, especially smartphones, has transformed the face of global learning, as everybody would be able to educate themselves without having to commute from home to school. This phenomenon has emerged a tutorial generation who has been educated by personalized education tools in the form of mobile-based and/or web-based applications that support any kind of knowledge they are interested in. This paper depicted a conducted research question whether those applications will vanish the traditional teaching model which was believed as high consuming in cost, time, and effort. The respondents were the students and lecturers of the vocational information technology program at UIN Ar-Raniry. During the research, they were given the top five independent learning applications related to programming courses, then they were requested to review at the same courses that was served by the most highly impact of MOOC services such as Coursera, Edx, and Udacity. The experiences of the participants were recorded and noted, then analyzed by QDA Miner software which summarized that ICT education tools assisted them to sharpen their understanding of the course content because they could learn at their own pace. Such education model is expected to empower a community within university preparing the formal institutions to adopt the new form of education. In the future, a further research will be needed on discussing a basic standard in the development of educational applications that is relevance to the curriculum.
\end{abstract}

Keywords: Education, Technology, Personalised Education Tool, Programming Teaching

\section{Introduction}

The presence of many computer applications in the internet era has transformed the shape of global education. Computer programming field is one of knowledge area, which has been affected by the emergence of information and communication technology (ICT). Most people whose expertise in this field gained knowledge not only from their formal education, but also from independent learning sources that widely spread on the net.

ICT utilization is supposed to elevate learning and proficiency in any educational sector. Its existence has established a virtual society who delivers the most recent knowledge applied in any related subject. This community of practice involves practitioners around the world who provide solutions in a tutorial format (Luksha and Peskov, 2014; Song, et al, 2013). Students as well as teachers commonly use the knowledge-base society services to improve their programming skills personally. Both of them have became a part of tutorial generation who trained themselves by using ICT services.

Personalized education tool (PET) is a part of ICT services for educational purpose. It runs both on the web or mobile platform. Since the booming of massive open online course (MOOC), PET has been widely used as a method in teaching computer programming. It is expected to be a supporting media for students who learn computer programming to upgrade their comprehension of a particular programming languages. Besides that, PET helps the learners in solving their homework or any project related to software development. As for teacher, it is intended as a model to structure teaching materials. The main advantage of PET is its ability to be

Corresponding Author: Fadhla Junus/ fadhlayn@ar-raniry.ac.id 
accessed in offline mode, consequently, users in a remote area would still be able to learn on the available subjects while they are disconnecting to the internet.

ICT services is predicted to replace the traditional teaching model. Lecture, textbook, personal tutorial, and apprenticeship will be replaced by MOOC, online multimedia libraries, virtual tutor, and virtual simulator, respectively (Luksha and Peskov, 2014). Moreover, digital technology serves extensive information as learning resource for researchers, teachers and students in collecting, analyzing, and disseminating data (Benson, 2015). If these speculations would be occured, do people still need going to school? As they would be able to study from their comforted places and in effortless circumstances.

The conducted research was supposed to answer the above assumption. As far as the author knows, many researchs clarified the ICT in education life but there are no any studies discussing on PET utilization for teaching and learning in computer programming field. Thus, the objective of this work is to construct a model to perform a comprehensive investigation of the effect of PET in higher education.

This work resulted in a recommendation of applying PET in learning as well as teaching computer programming. In the point of view of the respondents, they believed that PET should be adopted by educational institution because of its flexibility. Furthermore, the variety of learning style that was arranged in PET enticed them into a fun learning atmosphere.

The remainder of this article is constructed as follows: Section 2 provides related works to digital education. Section 3 reviews method that was used during the investigated research. Section 4 discusses the finding of this observation. Ultimately, the paper is concluded, and the future implications of this study are elaborated.

\section{Related Works}

Amalgamation of ICT with pedagogy system has altered the conventional learning process. In higher education, the lecture room has turned into student-centered learning that involved digital learning resources (Alonso et al, 2005; Kostolányová and Šarmanová, 2014). McLoughlin (2010) reports that the integration of social software into learning system has succesfully increased the quality of students' skill and their career preparation in UK, USA, and Australia.

Another supporting study (Gell-Mann (1996) cited in Alonso et al. (2005)) also states that optimization of instructional method can be achieved when learning is assisted and personalized. ICT devices are the promising defender of education system as they can be employed to personalize learning. The emergence of Open Educational Resources (OER) as a service of Web 2.0 conduced openness and collaboration on the net, because it can be accessed over any electronic tools and supplies abundant teaching material for free (Mikroyannidis et $a l$, 2011). The OER movement has built a personal learning environment (PLE) which enabled people to learn on any subject that they are interested in without regarding to place and time.

As PLE keeps growing, it raised many virtual societies that replaced the role of teachers. In a PLE system, every body could be both teacher and student depends on the skill level of a particular subject. Collaboration of knowledge and experience between senior and junior members play the most important aspect (Luksha and Peskov, 2014). An ideal PLE, according to an investigation (Glahn et al (2007) cited in Verpoorten et al.(2009)), should involve these two design principles : 1. Perspective of learners in their current learning context; 2. Contrasting information that allows the learner to evaluate the own actions.

MOOC, which has been existed more than a decade, is an example of PLE that is virtually supported by 142 universities. In accordance with report of International Strategy Office of Oxford University, the number of enrollment to MOOC provider is high, but the student who completed the course is low (Benson, 2015). 
Similarly, Luksha and Peskov (2014) mentioned that the most obvious drawback of MOOC is student motivation. According to them also, such condition is in contrast to the benefit of MOOC as an efficient online teaching methodology and provision of content from best global providers. To resolve this, Verpoorten et al explained in their research that "one key concept of PLE is motivation. It relies on three factors: perceived controllability, perceived value of the learning task and perceived self-efficacy for it."(Verpoorten et al, 2009). Therefore, each individual should consider those three aspects before deciding to be a part of PLE system.

In this smart phone era, the inquiry to educational softwares in supporting PLE system has been increased. As narrated in the Executive Summary of Future Agendas for Global Education, in section New Education: Stories from the Future, "The rising demand for personalized education from employers and investors will spur the development of personal education management systems (and respective market infrastructure). Development of personalized education tools will open a wealth of opportunities for 'concise' students that are ready to manage their own educational goals. The growing demand for authenticity, the search for a unique life path guided by deeper personal interests and the need for self-actualization, becomes a significant social phenomenon." (Luksha and Peskov, 2014, p.25). This statement binds the preceding finding by Dagger et al (2004) that "personalized education must provide tools and mechanisms in order to improve learner satisfaction with the received learning experience." (Dagger et al, 2004, p.2)

A study by Virvou and Alepis (2004) found that one disadvantage of web-based educational application is its loading time to launch a new page. This was caused by the limited bandwidth of ICT devices. Such trouble may be a burden for learners to reach their learning achievement because it wasted their valuable time. To eliminate this problem, the web-based educational software must also provide a mobile-based courseware which is still working in offline mode through learners' smartphone. At the current state, the appearance of PETs empower people to be directed remotely and asynchronously by human tutor out of the classroom.

\section{Methods}

PET softwares that were involved in this work are running on smart phone with Android operating system, because the majority of participants in this study use this platform in their daily activities. The crucial point in selecting these applications was the learning material must accommodate computer programming theme.

Further requirements embroiled in choosing PET applications were:

1. User Rating score is four stars;

2. They have been downloaded by more than 5,000 users;

3. They contain variety of the most widely used programming language, i.e. C++, Java, Phyton, and Web development series.

Based on the above preconditions, eight coursewares were chosen as illustrated in Table 1. Five applications were served by independent developer, while the other three of top MOOC providers.

Table 1 Summary of personalized education tools.

\begin{tabular}{llll}
\hline Application Name & $\begin{array}{l}\text { User rating } \\
\text { (in stars) }\end{array}$ & $\begin{array}{l}\text { Number of } \\
\text { download }\end{array}$ & $\begin{array}{l}\text { Number of } \\
\text { programming } \\
\text { language }\end{array}$ \\
\hline $\begin{array}{l}\text { MOOC provider } \\
\text { Coursera }\end{array}$ & 4 & 79,775 & Many \\
\hline Udacity & 4 & 19,029 & Many \\
\hline EdX & 4 & 13,199 & Many \\
\hline Independent developer & & & \\
\hline
\end{tabular}




\begin{tabular}{llll}
\hline Udemy & 4.1 & 58,109 & 7 \\
\hline Programming Hub & 4 & 46,770 & 17 \\
\hline Solo Learn & 5 & 33,155 & 11 \\
\hline Learn Programming & 4 & 12,130 & 30 \\
\hline Enki & 4.5 & 5,656 & 5 \\
\hline
\end{tabular}

This study was designed at the Vocational Information Technology Program of Education and Teaching Department of UIN Ar-Raniry, where the author works as a full time lecturer. Participants consist of 45 students who are interested in software engineering and also five lecturers who teach them.

Respondents were interviewed about their experiences on using the above PETs. They were suggested to enroll to similar programming course that were also taught in the classroom. The given period to accomplish their interactions with PET system were as long as they attend the face-to-face learning. During the four months of observation, the participants were required to express their point of view in such learning method. Therefore, they were given following three questions:

1. Will PET replace computer programming school?;

2. Is there any possibility to implement PET to other knowledge field? ;

3. What to expect to achieve an ideal PET?

Each recorded answer described respondent's opinions were scripted in text format. Accordingly, 50 scripting texts, which were saved as document files, imported to QDA Miner. Those 50 files were executed as variables. Each of them then associated as a case by adapting its file name. The transformation of recorded voice into text manuscript is compulsory, because the version of QDA Miner is free.

Next important step was coding each script by defining code name that was followed by picking code color. The code name functions as keywords that represented the given questions. Afterward, each case was manually scanned using the defined codes by pointing on appropriate sentences. The sentences were marked by the colors that were selected while defining the code.

Another way in analyzing the variables is by using Retrieve feature. It contains two retrieval modes which can be extracted by text and coding. Both features have searchable expression in which a specific string could be labeled. Moreover, the coding retrieval provides conditional item through which any boolean expression could be assigned. In final step, coding frequency feature was used to examine how often each code appears in the whole cases. The most frequent code shows the significance that leads to sum up this work.

In qualitative analysis, QDA Miner serves easier and faster method to gain significant data value because it can read alphanumerical data. Main obstacle in this analysis phase was time consuming during relating data to the defined code. The longer script of interview in each case, the more required time to inspect data manually.

\section{Results and Discussion}

Figure 1 shows the number of cases obtained from an analysis of the participants's answer to the first and the second of interview questions. It depicts the majority of respondents who agree to apply PET in computer programming learning and teaching as well as in other knowledge area (represented by the green graph). However, the number of participants who disagree nearly equal to those who has hesitation which is denoted by Probably label. 


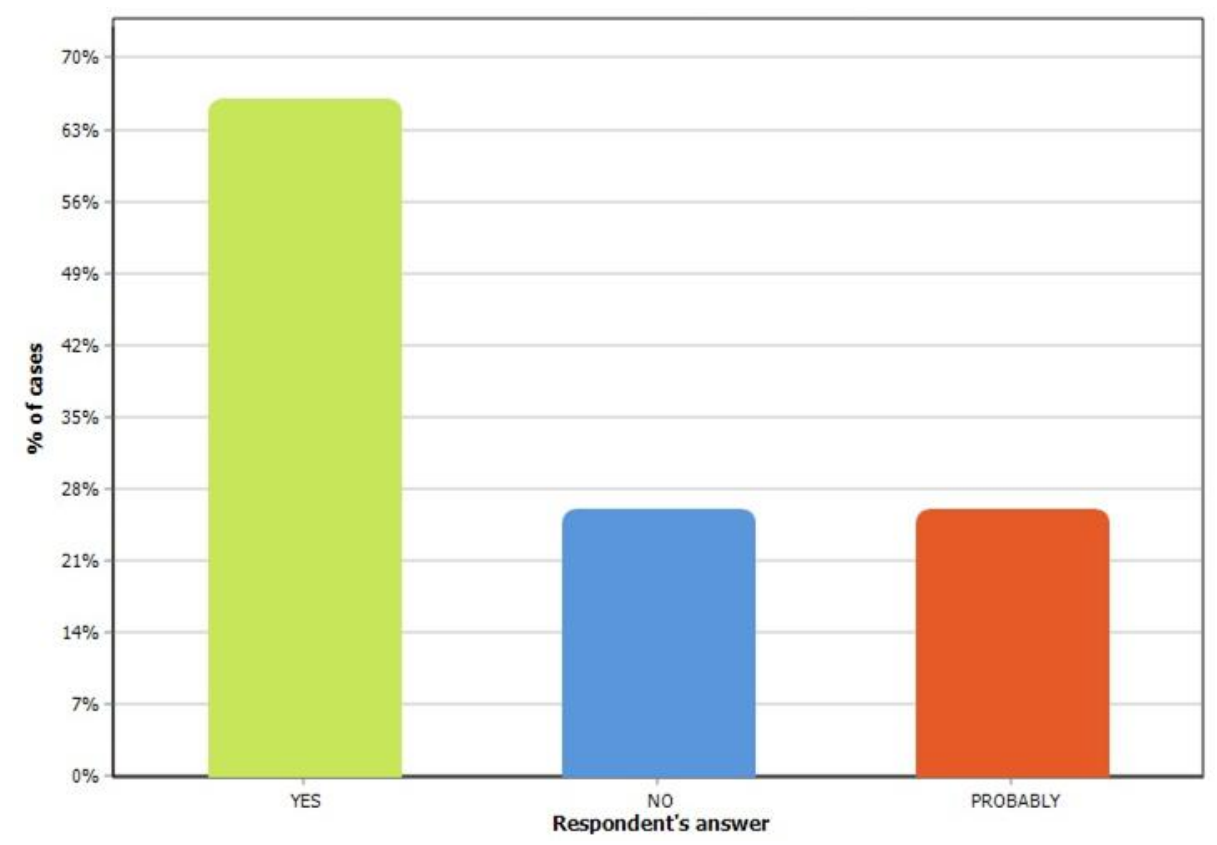

Figure 1 Cases percentage toward PET utilization to replace traditional class

The three charts above were generated based on the defined codes which were assigned in QDA Miner. The chosen name for the code used to analyze the cases must characterize the purpose of questions. Therefore, the word Replacement was given.

The code Replacement was classified into three sub-codes as Yes, No, and Probably that respectively reflected to agree, disagree, and unsure feeling. These sub-codes could appeared in the form of directly mentioned words or implicit sentences. The result of coding frequency analysis in code Replacement group was counted by QDA Miner that found the most frequent sub-code, Yes, occured 35 times. This value was represented by $66 \%$ of cases in the green graph of figure 1 above. As for the other two sub-codes, which were numbered in equal percentage (26\%), the occurance of both were 16 and 15 times.

Further analysis was made to look for the participant's expectation of ideal PET. It resulted the percentage of cases, as illustrated in Figure 2, which were coded according to the third question during interview phase.

The examination process in finding the most significant value of respondent's perception was done similarly to the previous analysis. It was started by giving name to the code called Expectation. The defined name symbolized the topic of third question, which then was also divided into three sub-codes as can be seen in the horizontal axis labels.

From the respondent's perception labels, it is clearly seen that $60 \%$ of cases prefer to PET due to its simplicity. The word 'on the go, easy, flexible and handy' showed up in the sentences for 31 times. The second significant value, which is equal to $42 \%$ of cases, was resulted by 21 occurences of Effectiveness code in the script. These two numbers indicated most respondents expected to have PET that can be accessed at any time and from any mobile devices although disconnecting from internet. While $28 \%$ of cases testified that participants supposed to have the full free edition of PET, besides that they hoped for achieving certificates after learning to use PET without any additional cost. 


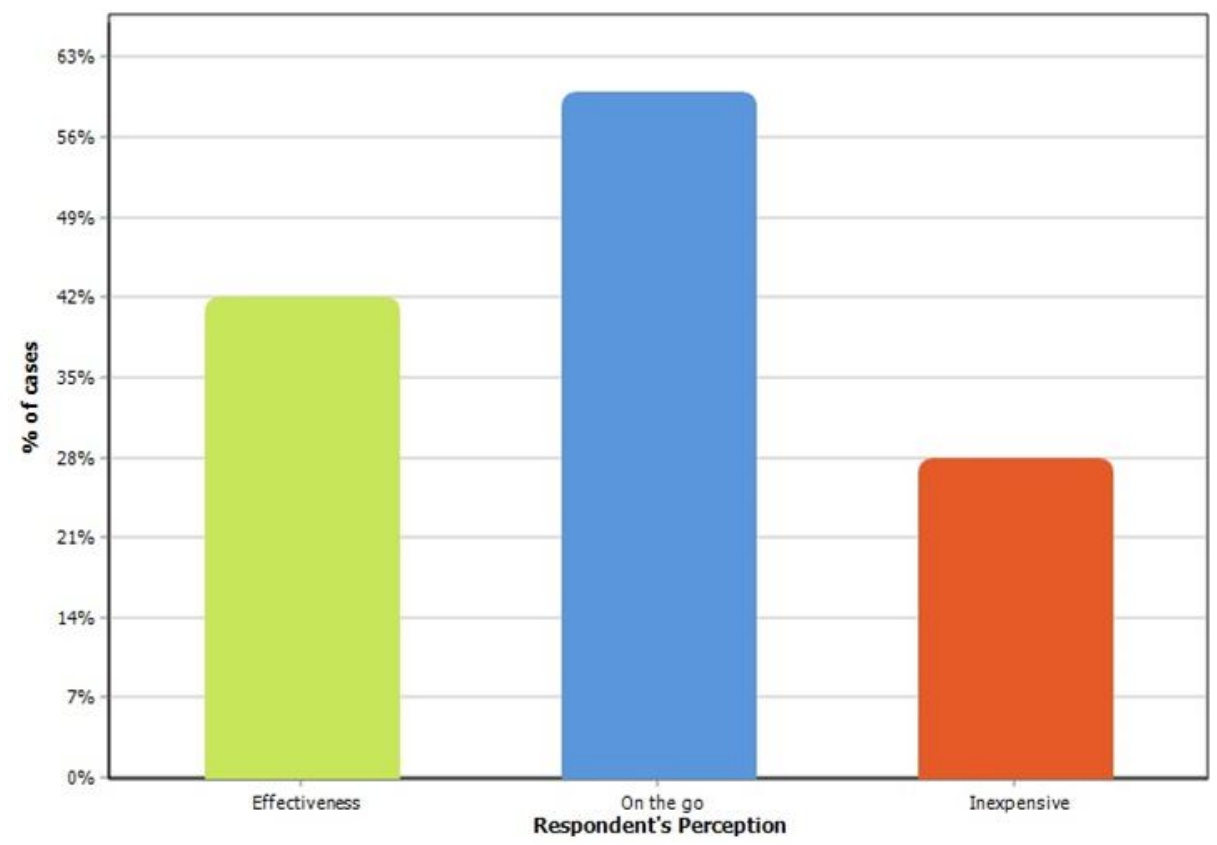

Figure 2 Cases percentage of expected benefit of ideal PET

From the two figures above can be concluded that the possibility of PET to change the way of people in learning is a very exciting proposition. The flexibility of PET enabled anyone to improve their skill and knowledge at anytime as the knowledge is on the hand. As mentioned in the introduction, so far no particular investigations study about PET utilization in learning and teaching computer programming. Although this is a small study, the results can be relatively implemented in traditional computer programming class.

Limitations found during this study were in the analysis of participant's answers, the hardest part was in interpreting the implicit sentences. Every sentence in the 50 interviewed scripts must read thoroughly before it was tagged to the suitable sub-codes. Moreover, the use of formulas to calculate the coding frequency by QDA Miner could not be initialized. Consequently, the interpretations of resulted figures may reveal a possible flaw.

\section{Conclusion}

PET utilization is inevitable to adapt in daily learning activities. According to the analysis of the interview script, the participants are able to learn at their own pace and time because PET offers flexibility in accessing study materials from any handheld devices with or without internet connection. Besides that, easy access to the latest knowledge can be achieved from the leading PET developers in modest way. Morever, the learning variety such quiz in a game format has attracted learners to spend more time to study. Although greater number of respondents believed that PET will replace the face-to-face classroom, the existence of it still can not be generally applied to traditional education model. The presence of real teacher is irreplaceable with virtual instructor, mainly for those whose less self-motivation. Additionally the issued certificate has not been legally recognized.

Even though this work focused on computer programming subjects, it is also applicable to other knowledge fields. Digital education is not something new, any educational institutions should prepare themselves to implement PET by taking part as a content provider or at least become a player who utilizes it in their academic systems. Therefore the institutions should give priority to legalize compatibility of PET content to regular course and also authorize certificate which were issued by PET providers. A future work is also needed by involving a larger number of participants who are interested in another field that still related to computer 
science. Besides that the mix method, both qualitative and quantitative, can be applied in data analysis to achieve more valid result.

\section{Acknowledgements}

Author would like to thank all the respondents who contributed information and experience to this study, which formed the basis for the conclusions made in this report.

\section{References}

Alonso, F., López, G., Manrique, D., \& Viñes, J. M. (2005). An instructional model for web- based e- learning education with a blended learning process approach. British Journal of educational technology, 36(2), 217-235.

Benson, K., 2015, International trends in higher education 2015. International Strategy Office, University of Oxford. Date of access: 18/10/2016.

https://www.ox.ac.uk/sites/files/oxford/International\%20Trends\%20in\%20Higher\%20Education\%202015.pdf

Dagger, D., Wade, V., and Conlan, O. 2004. Developing Active Learning Experiences for Adaptive Personalised eLearning. Paper presented at the 2nd International Workshop on Authoring Adaptive and Adaptable Educational Hypermedia.

Gell-Mann, M. (1996). A commentary to R Schank. In J. Brockman (Ed.), The third culture: beyond the scientific revolution. Touchtone Books. 167-180. Cited in Alonso, F., López, G., Manrique, D., \& Viñes, J. M. (2005). An instructional model for web- based e- learning education with a blended learning process approach. British Journal of educational technology, 36(2), 217-235.

Glahn, C., Specht, M., Koper, R., 2007, Smart indicators on learning interactions. In: E. Duval, R. Klamma, M. Wolpers (eds.) Creating new learning experiences on a global scale. LNCS, vol. 4753, (Berlin, Heidelberg: Springer), pp. 56-70. Cited in Verpoorten, D., Glahn, C., Kravcik, M.,Ternier, S., \& Specht, M., 2009, Personalisation of Learning in Virtual Learning Environments. In U. Cress, V. Dimitrova \& M. Specht (Eds.), Lecture Notes in Computer Sciences, Vol. 5794. (Berlin, Germany, Springer-Verlag), pp. 52-66.

Kostolányová, K., Šarmanová, J. (2014). Use of adaptive study material in education in elearning environment. The Electronic Journal of e-Learning, 12(2), 126-226.

Luksha, P., and Peskov, D., 2014, Future Agendas for Global Education. Executive Summary. Date of access: 16/10/2016. http://edu2035.org/pdf/GEF.Agenda_eng.pdf.

McLoughlin, C., Lee, M.J. (2010). Personalised and self regulated learning in the Web 2.0 era: International exemplars of innovative pedagogy using social software. Australasian Journal of Educational Technology, 26(1), 28-43.

Mikroyannidis, A., Okada, A., Little, S. and Connolly, T., 2011, Supporting the collaborative adaptation of Open Educational Resources: The OpenScout Tool Library. In: ED-MEDIA 2011: World Conference on Educational Multimedia, Hypermedia \& Telecommunications, Lisbon, Portugal, 27 June - 1 July, pp.3734-3739

Song, K., Kim, H., Seo, J., Kim, C. (2013). Development and Pilot Test of ICT in Education readiness indicators in the global context. KEDI Journal of Educational Policy, 10(2), 243-265

Verpoorten, D., Glahn, C., Kravcik, M., Ternier, S., \& Specht, M., 2009, Personalisation of Learning in Virtual Learning Environments. In U. Cress, V. Dimitrova \& M. Specht (Eds.), Lecture Notes in Computer Sciences, Vol. 5794. (Berlin: Springer-Verlag), pp. 52-66.

Virvou, M., Alepis, E. (2005). Mobile Educational Features in Authoring Tools for Personalised Tutoring. Journal Computers and Education, 44(1), 53-68. 